\title{
The Stress Felt by Leaders within the Modern Organization
}

\author{
Constanta POPESCU ${ }^{\star}$, Diana Nicoleta GEORGESCU ${ }^{\star \star}$, Georgiana Tatiana BONDAC ${ }^{\star \star \star}$
}

\begin{tabular}{l}
\multicolumn{1}{c}{ A R T I C L E I N F O } \\
\hline Article history: \\
Accepted June 2019 \\
Available online August 2019 \\
\hline JEL Classification \\
M12, 015 \\
Keywords: \\
Leader, Leadership, Stress, \\
Employee
\end{tabular}

\begin{abstract}
A B S T R A C T
When it comes to business, the notion of "normality" is changing from day to day and brings a shout of action to companies and leaders to adapt and reinvent themselves constantly. Major forces have completely changed the scenario. Growing companies is more volatile than ever. The global market, without limits, has completely destabilized the old corporate models. A new mix of generations and cultures has created teams and more diverse perspectives. Technology evolves in a new step. Furthermore, all these actions that target the leader, can induce him to a state of agitation, making him to become stressed. Thus, due to these aspects, the purpose of this article is to present the stress felt by leaders in the modern organizations.
\end{abstract}

Leadership has never been more important, but not even more complex. To survive and create longterm success - in such an unpredictable climate, leaders in all business areas need new models and new skills. In other words, the pendulum started, and generic approaches can no longer change their trajectory. For this reason, a specific approach is needed, centered on the dynamics of the emergence or perception of leadership difficulties and the ways in which they are assessed.

In the 1920s, leadership represented the leader's ability to impose his will on the leaders, inducing respect, loyalty and cooperation. In the early years, leadership was a process in which the work of many people was organized by a person so as to move in a certain direction. The following years bring with them the idea that leadership is the result of the ability to be persuasive and to direct people. Gradually it is considered that authority should be given naturally and spontaneously to the leader by the members of a group.

Consequently, there is a slight change of mindset (a thinking module) in the sense that leadership is regarded as an activity of influencing others in a certain direction. Later it is seen in terms of discretionary influence, in the sense that it can vary from individual to individual. In the next decade, the focus is on inspiring people to assume the actions proposed by the leader themselves. The great change occurs in the 1990s when leadership is defined as a relationship of mutual influence between leaders and its people, aiming at real changes that reflect their common goals.

The 21st Century brings major transformations, and conversational leadership is highly sought-after precisely because of the importance of communication and the relationship between the leader and his people (Hurley T., Brown J., 2010). Moreover, in the 21st century there is more than ever focus on individual resources: two boys created Google, another created Facebook, and another individual created Apple. This is the world of the 21st century: power is no longer the richest leader, with the greatest political influence, or with most people at your command. Today, the strongest one understands the enormous possibilities of each person and creates for his people the best conditions for them to make the most of their potential.

Of note is the shift from imposing to persuasion, influencing the leader, and then mutually influencing. In such an evolution, it was almost impossible to avoid the appearance of "servant leadership", participatory leadership and paternalist leadership. But, moreover, in this context - inevitably created the conditions of the emergence of this new concept: the permissive leader: capable, ingenious, coming with last-minute solutions, takes on the tasks of the team and seems to have answer to anything. This type of leader is seen by people as the rescuer who solves major problems at the last moment, pulls people out of the crisis and assumes the heaviest burdens (Myatt.M., 2012). The leader is therefore the creation of the last decade, a mixture of autocratic and democratic leadership styles.

The leader lets people assume what they want, does not punish and impose things, but does most of the tasks on their own, does not consult the members, and does not delegate the worst. This type of leader is 
more common than is believed, because most often the person in this condition is not aware of this. Most times, the leader feels caught in this condition once he understands the typology of his everyday interactions. As a permissive leader, the leader tends not to let people do it by themselves, make mistakes and learn from them, develop their ability to solve and evolve. The leader solves the problems at the last minute by himself, he is accustomed to people in this way, and proudly receives their praise after the crisis has passed. This scenario brings with it many disadvantages: starting from the ones listed on the evolution of the people, overloading the leader and achieving a general decrease in productivity.

Once such a frame has been created, the recovery is done with great weight. Waiver of hopes and expectations that feed on dependence and passivity is a complicated process because it requires interferences from both sides - the leader and the team. Team is a major factor in the birth of the leader. People expect someone to save them, wanting heroes, and pushing the hero freshly built to act unconsciously as the desired pattern. For too long, people have been intrigued by such a character who, in fact, discourages the natural evolution of everyone. The team is the one who starts the over of the leader through thoughts-force and attitudes like:

$>$ Leaders have the answers. They know what to do;

$>$ People do what they are told. They only need to be given good plans and instructions;

$>$ High risks require high control. When situations become complex and difficult, power must move to the top (to leaders who always know what to do).

At best, the consequence of this bidirectional approach is the repetitive sequence in which the leader comes to believe that he can find a simple solution on a complex issue on his own, with little help from the team. Most of the time, the help comes from just one person, a Batman's Robin under several faces, which always remains in his shadow. The rest of the people respect him deeply, admire him and hyperbolize him on this type of leader, but he creates a huge gap between them because they feel inferior and very ineffective around him. These feelings cause low self-esteem, avoidance behaviors and distance from people. Studies show that $64 \%$ of people feel dissatisfied with their workplace and because they do not feel sufficiently exploited by their leader (Helman, 2008). The permissive leader does not descend among them to encourage and encourage them to solve their own problems in order to enjoy the success of the solution, thus reducing the discrepancy created. Moreover, the superhero never recognizes that people need help, does not have the knowledge to solve a problem, and is in a huge deadlock. For this reason, although the team has an active role in creating such a leadership, it is ultimately the leader who is the most wrong but also the one who, by recruiting a good coach, can make major changes.

More and more often, the daily work of a true leader is directly related to the influence of a complex human system. This type of complexity puts the question of man's ability in the position of leadership to work effectively with the set of factors in dynamic interaction. Moreover, the leader needs to be perfectly aware of the position and role of his own influence in the very system he is leading. More specifically, it is necessary to understand the principle 0 of systemic thinking: "there is no outside".

The leader is completely submerged in those complex and interconnected relationships of today. There are no simple answers, and one person can not know what to do, especially if this person is under pressure from the group that expects it to come up with efficient and fast solutions. In this context, the team leader often develops what is known in the literature as "Rescuer Syndrome". This syndrome occurs when a person moves from effective to dysfunctional due to their high level of involvement in activity. The compulsive desire to please, to help, to make everything go well, makes him more receptive to the wishes of others and subreceptive to his personal needs. A leader affected by this syndrome can not say no, he often feels guilty and has unrealistic expectations. Manfred K. (2010) states that this behavior actually hides an addiction, just like cigarettes, alcohol, food or drugs.

Although there are often no immediate solutions to the problems presented to him, the superpower tends to feel uncomfortable if he does not come up with concrete court instances. Providing immediate solutions is not always the best thing to do. In this case, the leader completely forgets that the purpose of helping someone is to help that person discover her own way of operating.

The main problem is that the superhero leader becomes a victim and even an aggressor: played back in Karpman's classic triangle, a basic principle of human interaction. In creating the dramatic relationship illustrated by Karpman, three roles interact: The Persecuter, the Savior and the Victim.

In this situation, the leader is at first in the position of the Savior, but this position puts a lot of pressure on him and overwhelms him. For this reason, the leader becomes nervous, apathetic, sour, and team members are, without realizing it, aggressors. At this point, the leader moves from the savior to the overwhelmed victim, over whom to find out all the pressure and always expect immediate results. Unfortunately, in his zeal to help, he creates new difficulties and does not give the team members the chance to develop new skills, creativity or other capabilities to solve difficult cases.

By blocking this possibility of evolution, the leader enters, without intending, into the position described by Karpman, by the Aggressor. Lacking the perception that he has a capable team, developed and with diverse skills, the leader is again in the position to take on his responsibilities, and finally, again, in the position of Savior. 
Relationships in this type of interaction are particularly intense, giving the leader and team members a relatively "strong" dose of emotional or mental stimulation (as in the case of drugs). A fourth indirect role lies with the "Public," that is to certain non-team members, who participate passively or actively in the situation and could, if necessary, play a role in changing the course of events.

For the team, constant support is associated with the reduction of energy and initiative (Edelwich and Brodsky, 1980; Lakin Phillips, 1983; Hale, 1997; Thompson, 1998; O'Halloran and Linton, 2000; Miller, 2001); even with a progressive loss of vision and goals. Ultimately, the permissive leader could reach the point where he resolves rescue missions by himself, one after another. In this context, anxiety, emotional detachment and depression are very common. The chronic stress to which the permissive leader is exposed in this case is manifested in physical problems involving high blood pressure, diabetes, digestive problems and compromised immunity (Payne and Firth-Cozens, 1987; Heim, 1991; Ramirez et al., 1996). The physical stress the leader feels can reach the level where he shortens his life expectancy.

This type of leadership has, as we mentioned earlier, autocratic influences, as the leader makes decisions alone, without consulting the team, delegating responsibilities and exploring the potential of the members. Moreover, in the autocratic style, the focus is more on performance and not on people's development. The focus of power is on the leader, and all group interactions go to the leader (Mullins, 1999), communication is low and teamwork almost non-existent (Cole, 2004). Such a way of working causes conflicts, absenteeism, low productivity and poor quality of work.

We will try, in the following, to present possible solutions for getting out of the superhero role. These recommendations can not replace the changes brought about by the transformation of the leader due to the relationship with a coach who deals with the exact situation, but also the individual operating mechanisms of his client.

Permissive Leaderhsip is fueled by the illusion that someone can have control. Although we live in a world of complex, uncontrollable systems, many leaders feel the need to control everything that is happening around them. A good leader must admit that he does not know what to do in certain situations, that the best solutions are often the result of the ideas of several members. "I have no control and I have no answers" is what the permissive leader needs to say to others, but especially to him. Thus, it would be good for the permissive leader to put his cloak down, to descend among the people and ask for their help.

According to Argyris, having control is especially important in potentially threatening situations. In the case of the permissive leader, these situations are everywhere, which is why the need grows exponentially. The illusion of control actually occurs when the permissive leader overestimates his or her ability to influence a result. While it is important for a leader to trust his own strengths, it is more important for him to realize what resources he owns, what is his potential and how best to make the most of it. Thus, a better knowledge of personal recollections, of their own need for recognition, and acceptance of human weakness could make the permissive leader less dependent on the need for control, a less stressed and balanced person. In other words, in order to be a better leader, the permissive leader must accept and even use his human imperfections.

This is also the problem and the major potential resource of the permissive leader. Understanding the benefits of delegation but also personal and team barriers in connection with this practice could be a genuine and definitive exit from the permissive leadership typology and practices. Simply defined, delegation is the assignment of someone else's responsibility or authority, a management tool commonly used around the world. Delegation has been conceptualized as a tool for time management, decision-making, or a way to do more things through others. Although it plays an extremely important role in achieving performance, very few leaders understand this process as a way to develop, transform and invite people to a higher level of abilities and potential. A study in 2007 demonstrates the importance of delegation: because people feel they are involved in the decision-making process, they become more committed to performing the tasks associated with the decisions they have taken, resulting in an increase in productivity (Choi , 2007). Moreover, delegating responsibility is the most effective way that the leader ensures that people are truly engaged in activity, develops new skills, and increases their confidence in their own forces (Kuhnert, 2000).

Most barriers to effective delegation even put the leader, who has to face their anxieties about the distribution of responsibility in order to enjoy the benefits of a successful process. Here are some of its impediments (figure 1). 

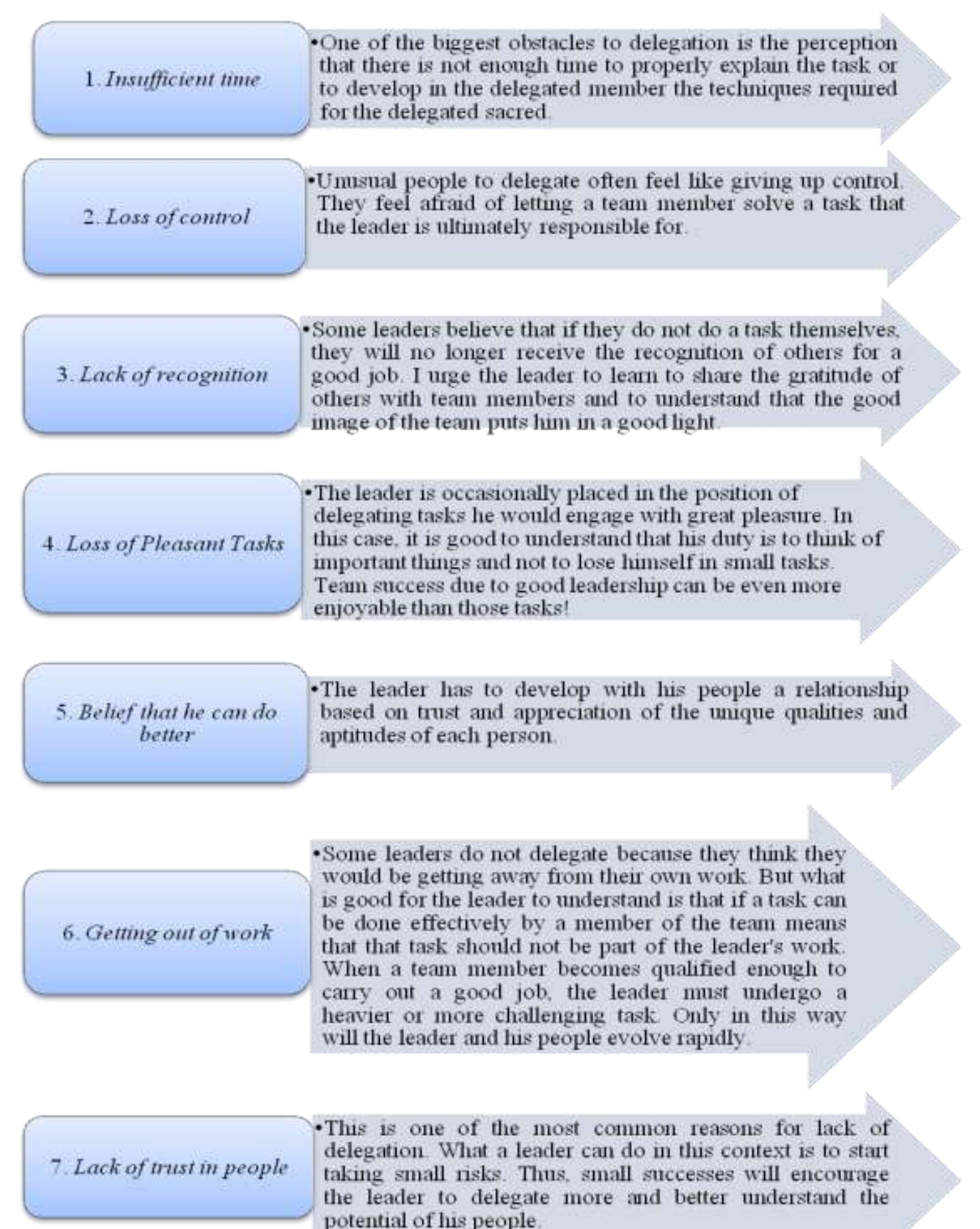

- This is one of the most common reasons for lack of delegation. What a leader can do in this context is to statt taking small risks. Thus, small successes will encourage the leader to delegate more and better understand the potential of his people.

Figure 1. Barriers imposed by leadership on effective delegation

Source: processed after Choi, S. (2007), Democratic leadership: the lessons of exemplary models for democratic governance. International Journal of Leadership Studies, 2(3), 243-262.

But the leader is not the only one who can be concerned about the delegation process. His people can also feel anxious about it. If the leader understands this, he can help them realize the benefits of delegation on both sides. Once they start to succeed, people will be more willing to take on additional responsibilities delegated by the leader. Below we will develop some of the barriers most often made by the team:

1. Insufficient time: Some team people may think they are already spending extra time on the company. This may be true, which is why it would be good for the leader to ensure that he / she correctly splits the tasks to himself / herself and to the team members.

2. Insufficient experience: Some people, especially newcomers or young students, may recognize that they do not have enough experience for the tasks to be done. In this case, it is good for the leader to start by 
delegating simple tasks so that they can gain confidence in their own forces. Once the success validates their skills, the leader can increase the weight of delegated tasks.

3. Fear of failure: Some team members may be afraid they will fail to carry out the delegated task. In this situation, I recommend that the leader explain to people that he will mentor during the task, that he will provide constant feedback to correct any mistakes that could have serious consequences. Moreover, it is good for the leader to provide support and encouragement to members who experience such an experience.

4. It is not their responsibility: to enjoy a successful team, it would be necessary for the leader to teach his people that everyone needs to be flexible and open to delegation. I recommend that the leader emphasize the importance of the pregnancy and the benefits that it will make, but also the fact that the skills and strengths of each member are necessary for the effective delivery of the task.

5. Fear of being a scapegoat: Some members tend to believe that the guilt will be thrown on them if anything, instead of being accepted by the leader, sometimes rightly so. It is good for the leader to make sure he does not sacrifice team members in case something goes wrong to save himself because this will only cause resentment and decrease in productivity across the team.

6. Reactions from colleagues: Some members of the team may hesitate to complete a task because of anxiety about the envy they can give birth to, or confront with other members. In this case I recommend that the leader ensure that the delegation was done with sufficient authority and that the division of tasks was done correctly.

One of the main causes that lead to this type of leader is the inappropriate use of empathy to the situation. The leader takes on the responsibilities of people trying to help them, and by doing so, sabotage their development. A leader in this posture must speculate the needs of his people to provide them with a framework appropriate to their evolution. Empathy is thus a fundamental resource for leadership. Leaders need empathy to show their people that they care about their needs and results.

Authentic leaders use empathy to effectively relate to their members and put themselves in their place (Walumbwa, Avolio, Gardner, Wernsing, \& Peterson, 2008). Empathy is also an essential part of emotional intelligence, which is considered by many researchers to be critical to a good leader (Bar-On \& Parker, 2000; George, 2000; Goleman, 1995). In effective companies, mentoring is what characterizes many of the younger leader-subordinate relationships where the leader assumes the role of mentor and feels compelled to subdue the young man to learning experiences, to provoke him but also to protect him (Yan \& Hunt , 2005). The challenge leads to the creation of intrinsic motivation, which produces more interest, enthusiasm, confidence, increased performance, persistence, creativity, self-esteem and well-being (Ryan and Deci 2000: Deci and Ryan, 1991;

It is proven that it is extremely important for the leader to be mindful of the needs of personal development and professional development of his people. In this way, people feel it as a responsibility to bring value back to both the leader and the entire organization, creating a win-win situation (Goldsmith M., 2003). In creating a climate of this kind, it is precisely the empathy of the leader, who is always careful to transform the people from his team, constantly inviting them to performance (Gentri, Weber, Sadri, 2007). Fortunately, empathy is not something inherent. She can be taught (Shapiro, 2002). If enough time and support is available, leaders can exponentially develop their empathic potential through coaching.

Once aware of the oscillation of roles in relation to team members, the leader can at the moment make small changes to accommodate the situation as long as he passes through his coach through the major transformation process that ensures a genuine change in behavioral and relationship patterns , immediately needed in the case of the superhero leader. Here are some ways to change:

> Applying the "mirror strategy". For example, when the leader begins to complain, in turn, of his own troubles, he signals that he is not complementary, but rather competitive in the same type of game with any team member who adopts such behavior. In this strategy, the leader needs to keep calm, not to rush into prejudging, and to realize that these behaviors are just symptoms of conflicting internal situations.

$>$ It is good that in such situations the leader will remain benevolent, attentive to facts, informative, questionable, neutral and professional. By asking for explanations of what is expected of each other in the relationship, it can help the interlocutor to "come back" to answer questions and participate in a more productive discussion. This approach is the approach centered on establishing a clear, classic contract in the coaching relationship.

$>$ Another way is when the leader tries to "validate" the team member by complimenting him on his or her motivation, intent or motivation, on how to deal with certain situations or on the courage it demonstrates. This value-based approach allows the member to gain a positive recognition that will replace the search for negative stimuli. Also, such validation allows the teammate to enter into a relationship by assuming an unforeseen and positive role.

\section{Conclusions}

What the leader can do right now is to understand that this oscillation produces psychological fatigue, tension fluctuations, or diffuse states of dissatisfaction, and remind members of their common goals and visions. 
Leaders react differently to the same stressful stimuli, due to the different perception of their nature and the different capacity to deal with. This is likely to lead to stress in varying degrees from individual to individual, thus disturbing the balance and performance of an organization. In this way the organizational stress is induced, in which case the manager must intervene to optimize it. Managing stress differentiated and nuanced, with the help of strategies appropriate to different forms of stress, the leader can help both him and his subordinates to change their perception of pregnancy and adapt it according to their abilities.

If shared, humor is also a good strategy to defuse the situation. However, he must lead with caution, in order not to reach what a member of the team could take as a derision, mockery, irony or sarcasm.

In the course of an interaction, if members of team are too "close" to each other for lack of space or in the absence of breaks between interventions, or if they interrupt, leaving the leader unable to complete his exposure and to breathe, to do with a major tension state that marks the shift from one role to another.

\section{References}

1. Baron, R., \& Parker, J. D. A. (2000), The hand-book of emotional intelligence.

2. Choi, S. (2007), Democratic leadership: the lessons of exemplary models for democratic governance. International Journal of Leadership Studies, 2(3), 243-262.

3. Cole, N. D. (2004), Gender differences in perceived disciplinary fairness.

4. George, J. M. (2000), Emotions and leadership: The role of emotional intelligence.

5. Goldsmith,M.(2004), Leadership Is a Contact Sport: The "Follow-up Factor" in Management Development

6. Helman R.(2008), ERBI Retirement Servey Human Relations, 53, 1027-1055 Journal of Counseling and Development, 79, $382-385$.

7. Karl W. Kuhnert.(2000), Developing people through delegation

8. O'Halloran, T. M., and Linton, J. M. (2000), Stress on the Job: Self-care Resources for Counselors. Journal of Mental Health Counseling, 22, 354-365.

9. Ryan, R. M., Deci, E.L.(2000), Intrinsic and Extrinsic Motivations: Classic Definitions and New Directions. Contemporary Educational Psychology, 25, 54-67.

10. Ryan, R.M., Deci, E. L.(2000), Self-determination theory and the facilitation of intrinsic motivation, social development, and well-being. American Psychologist, 55(1), 68-78.

11. Shaprio, J. (2002), How do physicians teachempathy in the primary care setting? Thomas J. Hurley and Juanita Brown(2010), Conversational Leadership: Thinking Together for a Change

12. Walumbwa, F. O., Avolio, B. J., Gardner, W. L.,Wernsing, T. S., \& Peterson, S. J. (2008), Authentic leadership: Development and validation of a theory-based measure. Journal ofManagement, 34, 89-126.

13. William A. Gentry, Ph.D., Todd J. Weber, Ph.D., and Golnaz Sadri, Ph.D. (2007), Empathy în the workpalce

14. Yan, J., \& Hunt, J. G. (2005), A cross cultural perspective on perceived leadership effectiveness.International Journal of Cross Cultural Management, 5, 49-66 